\title{
3 days vs. 7 days course of intravenous antibiotics for probable neonatal sepsis
}

\author{
Prashanth SN ${ }^{1}$, Rashmi N², Sandeep Patil ${ }^{3}$ \\ ${ }^{1}$ Dr. Prashanth S.N, Professor, ${ }^{2}$ Dr. N. Rashmi, Assistant Professor, ${ }^{3}$ Dr. Sandeep Patil, Assistant Professor, first and \\ second authors are affiliated with Department of Pediatrics, JSS Medical College and Hospital, JSS University, Mysore, \\ 3. Navodaya Medical College, Raichur, Karnataka, India.
}

Address for Correspondence: Dr. N. Rashmi, Assistant Professor in Pediatrics, JSS Medical College Hospital, JSS University, M.G. Road, Agahara, Mysore, Karnataka, India. Email id: dr.rashminagaraj@gmail.com

\begin{abstract}
Introduction: Duration of appropriate antibiotic therapy for neonatal sepsis does not have evidence-based guidelines. The rationale and safety of these recommendations have never been scientifically evaluated. Such untested approaches could result in the unnecessary use of antibiotics leading to increased cost of care, unneeded intravenous cannulation, prolonged hospitalization, mother-infant separation, increased colonization by pathogenic organisms and emergence of drug resistant strains. So, our objective was to compare 3 days v/s. 7 days course of intravenous antibiotics for probable neonatal sepsis in order to determine the optimal length of antibiotic therapy so that infants with genuine infection would be adequately treated while those without infection would not be over-treated. Methods: Randomized controlled trial (computerized randomization) done in the Neonatal Intensive Care Unit in a Tertiary care Teaching Hospital, Mysuru. About 150 neonates who were admitted in NICU for probable sepsis (clinical signs of sepsis and positive septic screening), who were on antibiotic therapy, with sterile blood culture at $3^{\text {rd }}$ day of admission were the participants. Neonates who fulfilled the inclusion criteria were randomly divided into two groups, i.e; those who received 3 days of antibiotics and those who received 7 day course of antibiotics. Successful therapeutic outcome was measured in terms of weight gain, no apparent signs of sepsis as ascertained by clinical examination \& no re hospitalization for sepsis. Results: Among the 150 eligible neonates in the study, (75 each in Groups 1 and 2, which were comparable with regard to term/preterm population and also early and late onset neonatal sepsis), there was no statistically significant difference in the outcome between the two groups in terms of mean age at presentation, gestational age, mode of delivery, age of onset of sepsis at presentation and relapse rates. However, the duration of hospital stay in group 1 babies who received 3 days of antibiotics was significantly shorter than in group 2 babies who received 7 days of antibiotics. Conclusion: 3 day course of antibiotics is enough for culture sterile probable sepsis, in both term and preterm babies and also in both early and late onset neonatal sepsis.
\end{abstract}

Keywords: Duration of hospital stay, Probable neonatal sepsis, Shorter antibiotic course.

\section{Introduction}

Duration of appropriate antibiotic therapy for neonatal sepsis does not have evidence-based guidelines. Standard textbooks recommend treatment end points of 7-14 days for blood culture positive or clinically probable sepsis. [1-3]. The rationale and safety of these recommendations have never been scientifically evaluated. Such untested approaches could result in the unnecessary use of antibiotics leading to increased cost of care, unneeded intravenous cannulation, prolonged

Manuscript received: $16^{\text {th }}$ January 2017

Reviewed: $24^{\text {th }}$ January 2017

Author Corrected: $30^{\text {th }}$ January 2017

Accepted for Publication: $7^{\text {th }}$ February 2017 hospitalization, mother-infant separation, increased colonization by pathogenic organisms and emergence of drug resistant strains [4-7].

In India, prolonged use of broad-spectrum antibiotics is leading to emergence of resistant bacteria and a rising incidence of severe fungal sepsis. Similar problems of antibiotic resistance have been reported in many countries, including both industrialized countries like North America, Europe and Australia [8-12] and in other developing countries [13]. Prolonged duration of initial empirical antibiotic treatment is also associated 
with increased rates of necrotizing enterocolitis and death in extremely low birth weight infants [14]. In uncomplicated probable neonatal sepsis, prolonged antibiotic therapy affects bacterial colonization and immune activation after birth which could have implications for later risk of allergy and asthma [15]

Objectives- To compare 3 days v/s. 7 days course of antibiotics for probable neonatal sepsis defined as clinical signs of sepsis with positive septic screening and blood culture being negative.

\section{Methods}

This study was conducted in the NICU, Department of Paediatrics, J.S.S Hospital, Mysore from November 2011 to April 2013.

Type of Study: Randomized controlled trial (computerized randomization).

Source of data: Neonates who were admitted in NICU for probable sepsis (clinical signs of sepsis with positive septic screening), who were on antibiotic therapy (according to the unit antibiotic policy) with sterile blood culture at $3^{\text {rd }}$ day of admission. Empirical antibiotic therapy would be unit-specific and determined by the prevalent spectrum of etiological agents and their antibiotic sensitivity pattern. Antibiotics once started would be modified according to the sensitivity reports. Based on the antibiotic review, we would start the newborns with probable neonatal sepsis empirically with Ciprofloxacin and Netilmycin. Blood culture sample would be collected with strict aseptic precautions. (cleaning the area with betadine, allowed to act for 30 seconds, followed by cleaning with spirit, with blood collected after thorough handwash and with sterile gloves on).

Inclusion criteria: Neonates of $>34 \mathrm{wks}$ gestation and $>2000$ gms at birth, with probable sepsis presenting with hypothermia or fever, lethargy, poor cry, feeding difficulties, depressed neonatal reflexes and a positive septic screen i.e; presence of any two of the four parameters namely, (a) Total leukocyte count (TLC) of $<5000 /$ cumm or $>15000 /$ cumm; (b) Immature to total neutrophil ratio of $>0.2$; (c) Absolute neutrophil count $<$ 1800/cumm; (d) C-reactive protein (CRP) $>1 \mathrm{mg} / \mathrm{dl}$. (Immunoturbidimetric method)

Exclusion Criteria: Babies with major malformations, severe birth asphyxia, bone, joint or deep-seated infection, who were already on antibiotics before coming to NICU, babies undergoing surgery, babies who were diagnosed as proven sepsis (culture positive sepsis) and blood culture negative but sick neonates.

Sample Size: Sample size for the present study was calculated as 75 in each group, so total of 150 , assuming $15 \%$ difference in improvement rate between two methods, and $95 \%$ improvement in one of the method, Alfa 0.05 , beta 0.2 and power of the study being $80 \%$.

Method of collection of data: All neonates admitted in the Neonatal Unit with birth weight $>2000$ grams and gestation age $>34$ weeks, to whom we started antibiotics for probable sepsis (both early onset and late onset) were eligible for study. The study was started after obtaining ethical committee clearance and informed consent was taken from all the parents of the babies included in the study. Cases were randomized at the end of $72 \mathrm{hrs}$ once the blood culture report received was sterile with positive septic screening. These babies underwent septic screening including complete blood count along with absolute neutrophil count, immature to total neutrophil ratio, CRP status (assessed by immunoturbidimetric method), urine for routine examination and culture sensitivity, CSF analysis and blood culture. At the end of $72 \mathrm{hrs,} \mathrm{if} \mathrm{culture} \mathrm{was}$ negative with positive septic screening, then cases were included in this study. Eligible babies were allocated to one of the two groups according to computerized randomised numbers.

Group1: These subjects did not receive further antibiotics after receiving the sterile blood culture report. Group2: These subjects received a total of 7 days of antibiotics. Neonates of the first group who received less therapy were observed in NICU or in the mothers ward for $24 \mathrm{hrs}$ following discontinuation of antibiotics prior to discharge and were re-examined as outpatients in 2 to 3 days after discharge and followed up after 1wk. Therapy was considered to be successful when there was weight gain, no apparent signs of sepsis as ascertained by clinical examination \& no rehospitalisation for sepsis. Blinding was done among the doctors in NICU who evaluated the babies. In our study, clinical signs alone were used to study the effect of antibiotics between the 2 groups. At each visit, information regarding episodes of illnesses in home after discharge was recorded. If any subject did not come for follow up, they were contacted by telephone. Parents were asked to report to our unit for any episode of illness till 15 days. 
Statistical analysis: Descriptive analysis was done by calculating mean, Standard Deviation (SD), proportions. Inferential statistics was done by chi- square test, independent $\mathrm{t}$ test. $\mathrm{P}<0.05$ was considered statistically significant. All calculations were done by SPSS version 13.0.

\section{Results}

This study was conducted in the Neonatal Intensive Care Unit in a tertiary Medical College Hospital from November 2011 to April 2013.

About 150 eligible babies of probable neonatal septicemia included in the study were allocated to 3-day and the 7-day antibiotic group (75 babies each) according to computerized random numbers. Baseline variables were comparable between the two study groups (Table 1). All cases were randomized to either group and completed their respective courses of appropriate antibiotics with full compliance. The use of antibiotics was similar between the two groups.

Table-1: Demographic distribution of patients.

\begin{tabular}{|c|c|c|c|c|c|}
\hline & & Group & $\mathbf{N}$ & Mean & $\begin{array}{c}\text { Std. } \\
\text { Deviation }\end{array}$ \\
\hline \multirow{2}{*}{\multicolumn{2}{|c|}{$\begin{array}{l}\text { Age in days when child presented } \\
\text { with sepsis symptoms }\end{array}$}} & $\begin{array}{c}\text { Group } \\
\text { 1(3days) }\end{array}$ & 75 & 4.33 & 3.310 \\
\hline & & $\begin{array}{c}\text { Group } \\
\text { 2(7days) }\end{array}$ & 75 & 3.89 & 2.403 \\
\hline Sex of baby & $\begin{array}{c}\text { Group } \\
\text { 1(3days) }\end{array}$ & $\%$ & $\begin{array}{c}\text { Group } \\
\text { 2(7days) }\end{array}$ & $\%$ & \\
\hline Male & 50 & 66.7 & 45 & 60 & \multirow{2}{*}{$\begin{array}{c}\mathrm{X}^{2} \text { value }=0.46 \\
\mathrm{p} \text { value }=0.5\end{array}$} \\
\hline Female & 25 & 33.3 & 30 & 40 & \\
\hline Total & 75 & 100 & 75 & 100 & \\
\hline
\end{tabular}

In our study, mean age (in days) of babies presenting with sepsis features in group 1 was 4.33 days and in group 2 was 3.89 days ( $\mathrm{t}$ value $=0.932 \mathrm{p}$ value $=0.353$. $\mathrm{P}$ value is not significant). There was no significant gender difference among the two groups. Late onset sepsis was more common than early onset sepsis.

Table-2: Comparison of symptom between two groups.

\begin{tabular}{|c|c|c|}
\hline Symptoms & Group1(N-75) & Group2(N-75) \\
\hline Fever & $18(24 \%)$ & $22(29.3 \%)$ \\
\hline Hypothermia & $4(5.3 \%)$ & $9(12 \%)$ \\
\hline Lethargy & $68(90.7 \%)$ & $69(92 \%)$ \\
\hline Feeding difficulties & $63(83 \%)$ & $70(93.3 \%)$ \\
\hline Poor cry & $28(37.3 \%)$ & $31(41 \%)$ \\
\hline Decreased neonatal reflexes & $14(18.7 \%)$ & $10(13.3 \%)$ \\
\hline
\end{tabular}

In group 1, 63 cases ( $83 \%)$ had leukocytosis of $>15000 /$ cumm, 51 cases $(67.9 \%)$ had positive CRP of $>1 \mathrm{mg} / \mathrm{dl}, 37 \mathrm{cases}$ (49.3\%) had I:T ratio of $>0.2,8$ cases $(10.6 \%)$ had leucopenia of $<5000 /$ cumm, and 6 cases $(7.9 \%)$ had ANC less than $1800 /$ cumm.

In group 2, 65 cases $(86.5 \%)$ had leukocytosis of $>15000 /$ cumm, 62 cases $(82.5 \%)$ had positive CRP of $>1 \mathrm{mg} / \mathrm{dl}, 36$ cases $(47.9 \%)$ had I:T ratio of $>0.2,10$ cases $(13.3 \%)$ had leucopenia of $<5000 /$ cumm and 9 cases $(11.9 \%)$ had ANC less than 1800 /cumm. $92 \%$ of the cases in Group 1 improved compared to $96 \%$ in group 2 . So, it was noticed that there was no statistically significant difference in proportion of patients showing clinical improvement after 3 days of antibiotic compared to 7 days of same antibiotic therapy.

Gestational age - wise outcome is shown in Table 3. It is apparent that, there was no statistically significant difference among the two groups with respect to gestational age. 
Table-3: Gestational age wise outcome of cases between two groups.

\begin{tabular}{|c|c|c|c|c|c|c|c|}
\hline & \multicolumn{3}{|c|}{ 3 days } & \multicolumn{3}{c|}{ 7 days } & \\
\hline & $\mathbf{n}$ & Improved & Rate & $\mathbf{n}$ & Improved & Rate & X2, p \\
\hline Term & 62 & 56 & 90.3 & 60 & 58 & 96.7 & $2,0.2$ \\
\hline Pre term & 13 & 13 & 100 & 15 & 14 & 93.3 & $0.3,0.5$ \\
\hline Total & $\mathbf{7 5}$ & $\mathbf{6 9}$ & $\mathbf{9 2}$ & $\mathbf{7 5}$ & $\mathbf{7 2}$ & $\mathbf{9 6}$ & \\
\hline
\end{tabular}

\section{$\mathrm{P}=0.8$ (logistic regression)}

There was no statistically significant difference among two groups with respect to mode of delivery. Also, there was no statistically significant difference among the two groups with respect to the age of onset of presentation. (Early and late onset sepsis) (Table 4).

Table-4: Comparison of outcome among two groups according age of onset of sepsis at presentation.

\begin{tabular}{|c|c|c|c|c|c|c|c|}
\hline & \multicolumn{3}{|c|}{ Group 1(3 days) } & \multicolumn{3}{c|}{ Group 2(7 days) } & \\
\hline & $\mathbf{n}$ & Improved & Rate & N & Improved & Rate & X2, $\mathrm{p}$ \\
\hline EOS & 32 & 30 & 93.8 & 38 & 36 & 94.7 & $0.03,0.6$ \\
\hline LOS & 43 & 39 & 90.7 & 37 & 36 & 97.3 & $1.5,0.2$ \\
\hline Total & 75 & 69 & 92 & 75 & 72 & 96 & \\
\hline
\end{tabular}

$\mathbf{P}=0.9$ (logistic regression)

It was observed that there was no significant difference in the rate of relapse in improved cases among the 2 groups (Table 5).

Table-5: Comparison of relapse between two groups.

\begin{tabular}{|c|c|c|}
\hline Group & Total & Relapse (\%) \\
\hline Group1 (3 day) & 69 & $4(5.8)$ \\
\hline Group2 (7 day) & 65 & $3(4.6)$ \\
\hline Total & 134 & $7(5.2)$ \\
\hline
\end{tabular}

$\mathrm{X}^{2}$ value $=0.1, \mathrm{p}$ value $=0.9$

Rate of relapse observed in group which received 3 days antibiotic treatment is not significantly different compared to the group which received 7 days of antibiotics.

Mean duration of hospital stay in group 1 was 4.4 days compared to 7.6 days in group 2, which was statistically significant. ( $\mathrm{p}$ value - <0.0001). (Table 6)

Table-6: Mean duration of stay in hospital among two groups.

\begin{tabular}{|c|c|c|c|}
\hline & \multicolumn{2}{|c|}{ Duration of stay } & \\
\hline Group & Mean & SD & t value and p value \\
\hline Group1 (3 day) & 4.4 & 1.72 & 12.83 \\
Group2 (7 day) & 7.6 & 1.31 & $<\mathbf{0 . 0 0 0 1}$ \\
\hline
\end{tabular}


Original Research Article

\section{Discussion}

In our study, there was no significant difference in the treatment failure rates with 3 days vs 7 days of antibiotics for uncomplicated probable neonatal sepsis. These observations were similar to these in other studies [16-18].

We included only symptomatic babies and did not include asymptomatic babies with maternal risk factors as they are likely to have a very low baseline event rate and would show a favorable response irrespective of duration of antibiotics.

This is in contrast to previous serial CRP based studies which included babies irrespective of symptomatology [19-22].

In the present study, $63.3 \%$ cases were males as comparable with studies done by Saxena et al (59.17\%) [23] and Gupta et al (64.7\%) [24], all studies showing male predominance. We assessed improvement clinically in contrast to study done by Lee et al where serial CRPs were done to stop antibiotics at $3^{\text {rd }}$ day.

It was observed that there is no significant relapse after stopping antibiotics at $3^{\text {rd }}$ day compared to the control group in which 7 days of antibiotics were given. Also, the mean duration of stay in the hospital in group 1 was significantly lesser when compared to that in group 2 (Table 6). These observations were comparable with other studies $[16,22]$.

Our study didn't show significant difference in improvement in 3 days Vs 7 days of antibiotics for probable sepsis in both early and late onset sepsis among both term and preterm infants.

Similar observation were also found in other studies [16]. Mode of delivery did not make a difference in the outcome in the 2 groups.

So, it could be concluded that, in both preterm and term babies, a 3 day course of antibiotics is enough for culture sterile probable sepsis (both early and late onset). And also, it could significantly reduce the duration of stay in the hospital.

Funding: Nil, Conflict of interest: None initiated, Perission from IRB: Yes

Conflict of interest (COI) Statement: The authors have no conflicts of interest relevant to this article.

\section{References}

1. Schelonka RL, Freij BJ, McCrecken GH Jr. Bacterial and fungal infections. In: MacDonald MG, Seshia MMK, Mullett MD, editors. Avery's Neonatology. Pathophysiology and management of the newborn. 6th ed. Philadelphia: Lippincott William Wilkins. 1999. p. $1235-75$

2. Klein JO. Bacterial sepsis and meningitis. In: Remington JS, Klein JO, editors. Infectious Diseases of Fetus and Newborn Infant. 5th Ed. Philadelphia: WB Saunders \& Co. 2001.p.943-99.

3. Dear P. Neonatal infections: Infections in the newborn. In: Rinnie JM editor. Roberton's Textbook of Neonatology. 4th ed. Elsevier Churchill Livingstone; 2005. p. 1011-1093.

4. Hammerschlag MR, Klein JO, Herschel M, Chen FC, Fermin R. Patterns of use of antibiotics in two newborn nurseries. N Engl J Med. 1977 Jun 2;296(22):1268-9.

5. Philip AG, Hewitt JR. Early diagnosis of neonatal sepsis. Pediatrics. 1980 May;65(5):1036-41.

6. Goldmann DA, Leclair J, Macone A. Bacterial colonization of neonates admitted to an intensive care environment. J Pediatr. 1978 Aug; 93(2):288-93.

7. Lacey RW. Evolution of microorganisms and antibiotic resistance. Lancet.1984Nov3;2(8410):1022-5.

8. Gordon A, Isaacs D. Late-onset infection and the role of antibiotic prescribing policies. Curr Opin Infect Dis. 2004 Jun;17(3):231-6.

9. Lautenbach E, Patel JB, Bilker WB, Edelstein PH, Fishman NO. Extended-spectrum beta-lactamaseproducing Escherichia coli and Klebsiella pneumoniae: risk factors for infection and impact of resistance on outcomes. Clin Infect Dis. 2001 Apr 15;32(8):1162-71. Epub 2001 Mar 26.

10. Gupta A. Hospital-acquired infections in the neonatal intensive care unit--Klebsiella pneumoniae. Semin Perinatol. 2002 Oct;26(5):340-5.

11. Royle J, Halasz S, Eagles G, Gilbert G, Dalton D, Jelfs $\mathrm{P}$, et al. Outbreak of extended spectrum beta lactamase producing Klebsiella pneumoniae in a neonatal unit. Arch Dis Child Fetal Neonatal Ed. 1999; 80: F64-F68. 
12. Pessoa-Silva CL, Meurer Moreira B, Camara Almeida V, Flannery B, Almeida Lins MC, Mello Sampaio JL, et al. Extended-spectrum beta-lactamaseproducing Klebsiella pneumoniae in a neonatal intensive care unit: Risk factors for infection and colonization. J Hosp Infect. 2003; 53: 198-206.

13. Jain A, Roy I, Gupta MK, Kumar M, Agarwal SK. Prevalence of extended-spectrum beta-lactamaseproducing Gram-negative bacteria in septicaemic neonates in a tertiary care hospital. J Med Microbiol. 2003 May;52(Pt 5):421-5.

14. Cotten CM, Taylor S, Stoll B, Goldberg RN, Hansen NI, Sánchez PJ, Ambalavanan N, Benjamin DK Jr; NICHD Neonatal Research Network. Prolonged duration of initial empirical antibiotic treatment is associated with increased rates of necrotizing enterocolitis and death for extremely low birth weight infants. Pediatrics. 2009 Jan;123(1):58-66. doi: 10.1542 / peds. 2007-3423.

15. Marra F, Lynd L, Coombes M, Richardson K, Legal M, Fitzgerald JM, Marra CA. Does antibiotic exposure during infancy lead to development of asthma?: a systematic review and metaanalysis. Chest. 2006 Mar; 129 (3):610-8.

16. Saini SS, Dutta S, Ray P, Narang A. Short course versus 7-day course of intravenous antibiotics for probable neonatal septicemia: a pilot, open-label, randomized controlled trial. Indian Pediatr. 2011 Jan;4 8 (1): 19-24. Epub 2010 Aug 1.

17. Kaiser JR, Cassat JE, Lewno MJ. Should antibiotics be discontinued at 48 hours for negative late-onset sepsis evaluations in the neonatal intensive care unit? J Perinatol. 2002 Sep;22(6):445-7.
18. Isaacs D, Wilkinson AR, Moxon ER. Duration of antibiotic courses for neonates. Arch Dis Child. 1987 Jul;62(7):727-8.

19. Ehl S, Gering B, Bartmann P, Högel J, Pohlandt F. C-reactive protein is a useful marker for guiding duration of antibiotic therapy in suspected neonatal bacterial infection. Pediatrics. 1997 Feb; 99 (2): 216-21.

20. Bomela HN, Ballot DE, Cory BJ, Cooper PA. Use of C-reactive protein to guide duration of empiric antibiotic therapy in suspected early neonatal sepsis. Pediatr Infect Dis J. 2000 Jun;19(6):531-5.

21. Khashabi J, Karamiyar M, Taghinejhad H, Shirazi M. Use of Serial C-reactive Protein Measure-ments for Determination of the Length of Empiric Antibiotic Therapy in Suspected Neonatal Sepsis. Iranian Journal of Medical Sciences. 2015 Oct 4; 29(1): $31-5$.

22. Lee WE, Chan ML, Young BWY. Reducing hospitalization and antibiotic use in suspected early neonatal sepsis through serial measurements of Creactive proteins. HK J Pediatr. 2005;10:3-9.

23. Saxena S., Anand N.K., Saini L., et al. Bacterial infections among home delivered neonates. Clinical picture and bacteriological profile. Indian Pediatr. 1980 Jan;17(1):17-24.

24. Gupta P, Murali MV, Faridi MM, Kaul PB, Ramachandran VG, Talwar V. Clinical profile of klebsiella septicemia in neonates. Indian J Pediatr. 1993 Jul-Aug;60(4):565-72.

\section{How to cite this article?}

Prashanth SN, Rashmi N, Sandeep Patil. 3 days vs. 7 days course of intravenous antibiotics for probable neonatal sepsis. J PediatrRes.2017;4(02):149-154.doi:10.17511/ijpr.2017.i02.11. 